CrossMark

$\leftarrow$ click for updates

Cite this: DOI: $10.1039 / \mathrm{c5ce00905g}$

Received 8th May 2015,

Accepted 24th June 2015

DOI: $10.1039 / \mathrm{c} 5 \mathrm{ce} 00905 \mathrm{~g}$

www.rsc.org/crystengcomm

\title{
Thermodynamic parameters of the pedal motion in the crystal structures of two bromomethylated azobenzenes $\dagger$
}

\author{
Christophe M. L. Vande Velde, ${ }^{\star a}$ Matthias Zeller ${ }^{\mathrm{b}}$ and Vladimir A. Azov*c
}

\begin{abstract}
Two bromomethylated azobenzene derivatives were characterized by X-ray crystallography at $100 \mathrm{~K}$ after fast cooling, and showed disorder of the central $\mathrm{N}$-atoms. The structures were re-determined over a range of temperatures, providing evidence for dynamic disorder due to pedal motion of the central $\mathrm{N}=\mathrm{N}$ bond. Using van't Hoff plots, thermodynamic parameters for the pedal motion were determined. Computationally very cheap Atom-Atom-Force Field (AA-CLP) calculations were employed, which showed that the differences in dynamic disorder enthalpy between the two compounds are predominantly due to intermolecular interactions. AA-CLP calculations and gas phase electronic structure calculations were employed to show the link between intermolecular interactions and activation energy for pedal motion.
\end{abstract}

\section{Introduction}

Similar to compounds with $\mathrm{C}=\mathrm{C}$ double bonds, azobenzenes ${ }^{1}$ can exist as two different configurational isomers of the $\mathrm{N}=\mathrm{N}$ bond; the $(E)$-isomer tends to be planar and about $50 \mathrm{~kJ} \mathrm{~mol}^{-1}$ more stable than the $(Z)$-isomer, ${ }^{2}$ which presents an angular geometry for steric reasons. Photochromic properties of azobenzenes originate in the photochemical isomerization between $(E)$ - and $(Z)$-states. ${ }^{3}$ This isomerization leads to a considerable reduction in length, making azobenzenes useful building blocks for the introduction of large scale motion on the molecular level, ${ }^{4}$ such as photocontrollable cation binders ${ }^{5}$ and catenanes, ${ }^{6}$ photomechanically controlled $\pi$-conjugated systems, ${ }^{7}$ and even Brønsted bases. ${ }^{8}$ Being interested in the construction of azobenzene-tetrathiafulvalene macrocycles, ${ }^{9}$ we have prepared several bromomethylated azobenzene derivatives as precursors. Two of these derivatives, (E)-3,3'-bis(bromomethyl)azobenzene 1 and $(E)-4,4^{\prime}$-bis(bromomethyl)azobenzene 2, were shown to display dynamic disorder in the solid state due to the pedal motion of the central double bond (Fig. 1).

Disorder in crystals can either be static or dynamic. When static, the overall population of the disordered moieties is locked in during the crystallization process. When it is

\footnotetext{
${ }^{a}$ Faculty of Applied Engineering, University of Antwerp, Salesianenlaan 90, 2660 Hoboken, Belgium. E-mail: christophe.vandevelde@uantwerpen.be

${ }^{b}$ Youngstown State University, One University Plaza, Youngstown, OH 44555 3663, USA

${ }^{c}$ University of Bremen, Department of Chemistry, Leobener Str. NW 2C, D-28359 Bremen, Germany. E-mail: vazov@uni-bremen.de

$\dagger$ Electronic supplementary information (ESI) available: X-ray crystallography experimental details (Table S1 and S2), details of electronic structure calculations, and CIF files. CCDC 1063365-1063381. For ESI and crystallographic data in CIF or other electronic format see DOI: $10.1039 / \mathrm{c} 5 \mathrm{ce} 00905 \mathrm{~g}$
}

dynamic, however, populations change with temperature. Depending on the activation energy of the process, the speed of cooling can influence the temperature at which the equilibrium becomes frozen in, and the population ratio of the two conformers at which this happens. Measurements at several temperatures can allow to find out whether the

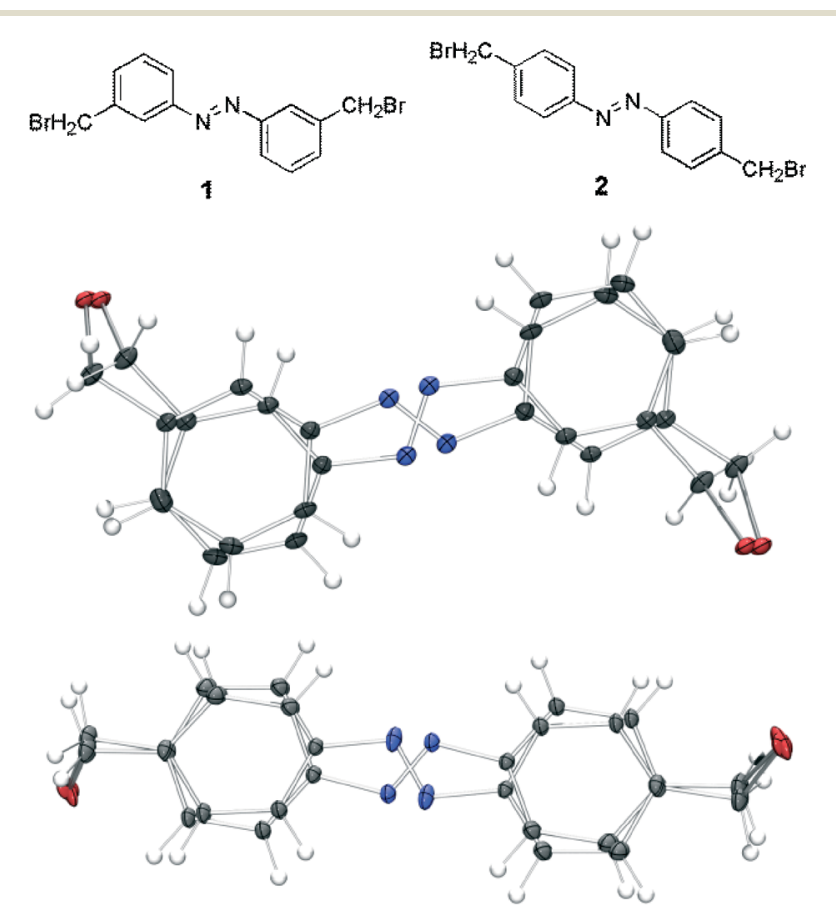

Fig. 1 Plot of the two conformers of 1 (top) and 2 (bottom) in the crystal structure at $90 \mathrm{~K}$. Displacement ellipsoids are at the $50 \%$ level. 
equilibrium is static or dynamic, and to determine its thermodynamic parameters.

Dynamic behavior of molecules in the crystal phase has been the subject of considerable interest in the past. Bicycle pedal motion ${ }^{10}$ in double bond compounds, ranging from azobenzenes $^{11}$ over stilbenes ${ }^{12}$ to diphosphanes, ${ }^{13}$ has been implicated in causing apparently shorter double bonds, ${ }^{14}$ inducing of concerted motion in crystals, ${ }^{15}$ as well as influencing the gas adsorption process ${ }^{16}$ or solvent exchange in MOFs. $^{17}$ Additionally, it can influence the photodimerisation process of olefins, where it either helps to overcome the usual topochemical constraints, ${ }^{18}$ or, on the contrary, prevents cyclizations where they would be expected to occur. $^{19}$

\section{Results and discussion}

\section{van't Hoff plots and thermodynamic parameters}

In the crystal structures of compounds 1 and 2, the typical disorder due to pedal motion of the $\mathrm{N}=\mathrm{N}$ moiety, reported previously for two other azobenzene derivatives, ${ }^{11}$ is observed. Exploratory structure determinations at room temperature and at $100 \mathrm{~K}$ with slow cooling yielded quite different results for the populations of the two conformers for $\mathbf{1}$, whereas for 2 the difference was rather small. This observation prompted us to further study the thermodynamics of the pedal motion in both compounds. There are three examples in the literature on the study of thermodynamics of "pedaling" conformers by means of a van't Hoff plot analysis ${ }^{20,21}$ (compounds 3-5), which all point to entropic and enthalpic differences between the two conformers being constant throughout the temperature range being studied. In other words, the van't Hoff plot, which displays $\ln (K)$ with respect to $1 / T$, is linear, down to a point where the equilibrium freezes in due to the temperature of the $k T$ bath becoming insufficient to overcome the activation energy for the pedal motion. However, a fourth example is known in the literature (distyrylbenzene (DSB) derivative 6) for which the van't Hoff plot is not linear, having distinctly different $\Delta H$ and $\Delta S$ values at high and low temperatures. ${ }^{22}$

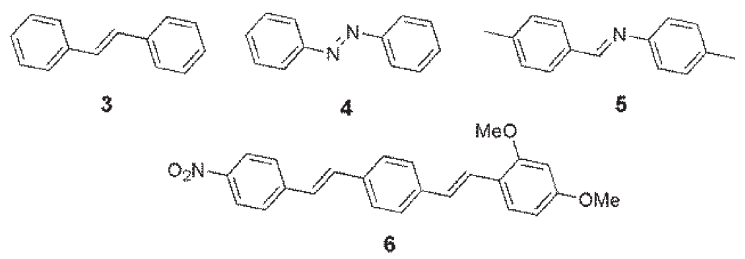

We wanted to explore a larger number of compounds to see whether another example could be found that would behave in a similarly anomalous manner. The data for the enthalpic and entropic differences obtained can in any case be compared to those derived from the van't Hoff plots of earlier studies. These enthalpy and entropy differences between the two conformers, calculated from the literature data for the examples previously reported, are presented in Table 1.
Table 1 Enthalpy and entropy differences for different compound classes

\begin{tabular}{lcc}
\hline & $\begin{array}{l}-\Delta H \\
\left(\mathrm{~kJ} \mathrm{~mol}^{-1}\right)\end{array}$ & $\begin{array}{l}\Delta S \\
\left(\mathrm{~J} \mathrm{~K}^{-1} \mathrm{~mol}^{-1}\right)\end{array}$ \\
\hline Stilbene 3 $^{20}$ & 4.1 & -0.5 \\
Azobenzene 4 $^{20}$ & 2.4 & -3.2 \\
4,4'-Dimethyl-benzylideneaniline 5 $^{21}$ & 1.7 & +3.0 \\
2,4-Dimethoxy-4'nitro DSB 6 $(<291 \mathrm{~K})^{22}$ & 7.1 & +16.0 \\
2,4-Dimethoxy-4'nitro DSB 6 $(>291 \mathrm{~K})^{22}$ & 14.9 & +43.1 \\
\hline
\end{tabular}

We find that the disorder in 1 is dynamic, with the equilibrium frozen in by cooling to $100 \mathrm{~K}$ at $4 \mathrm{~K} \mathrm{~min}^{-1}$. Upon stepwise reheating it thaws out again at a temperature of around $120 \mathrm{~K}$. At temperatures above $120 \mathrm{~K}$ (i.e. $T^{-1}<$ $0.00833 \mathrm{~K}^{-1}$ ), the van't Hoff plot (Fig. 2, blue markers) for 1 shows a single straight line, which indicates that the enthalpic and entropic differences between the conformers remain unchanged throughout the entire temperature trajectory. Since the slope of the van't Hoff plot is given by $-\Delta H / R$ and the intersection with the $y$-axis yields $\Delta S / R$, it is easy to calculate these quantities from the linear regression line (see Table 2 below).

For 2, the crystal structure was determined from room temperature data, and the crystal was also quickly cooled to $100 \mathrm{~K}$. The decrease in the population of the minor conformer on going from $293 \mathrm{~K}$ to $100 \mathrm{~K}$ was slight. Nevertheless, cooling of the crystal to $90 \mathrm{~K}$ at $4 \mathrm{~K} \mathrm{~min}^{-1}$, and then recording X-ray diffraction data upon reheating it in $50 \mathrm{~K}$ steps also afforded a linear van't Hoff plot (Fig. 2, red markers). This structure thaws out around $200 \mathrm{~K}$. In the same way as for 1 , the enthalpic and entropic differences appear to remain constant throughout the temperature range (Table 2).

\section{Crystal packing}

In the crystal, compound $\mathbf{1}$ forms layers of herringbonepacked molecules with their long axis oriented along the $a$-direction and connected to the next layer by type II halogen interactions; ${ }^{23}$ an arrangement that forms a double layer predominantly comprising bromine atoms, perpendicular to the $a$ axis. The packing of 2 is different, entailing layers perpendicular to the $c$ direction, which in turn consist of columns of molecules, which are oriented in the $b$ direction, and parallel displaced along their long axis. Alternating layers perpendicular to $c$ have the long axis of the molecule oriented at an angle of nearly $90^{\circ}$. The overall involvement of the bromine atoms in the crystal packing is more or less the same as in 1: perpendicular to the $c$ direction bromine-rich layers are held together by type II halogen interactions.

\section{Influence of crystal packing on thermodynamic parameters}

The effect of the crystal packing on the pedal motion can be seen in the slope of the van't Hoff plots, where we find that the enthalpic difference between the two conformers of 2 is much larger than that of 1. In order to explain this 


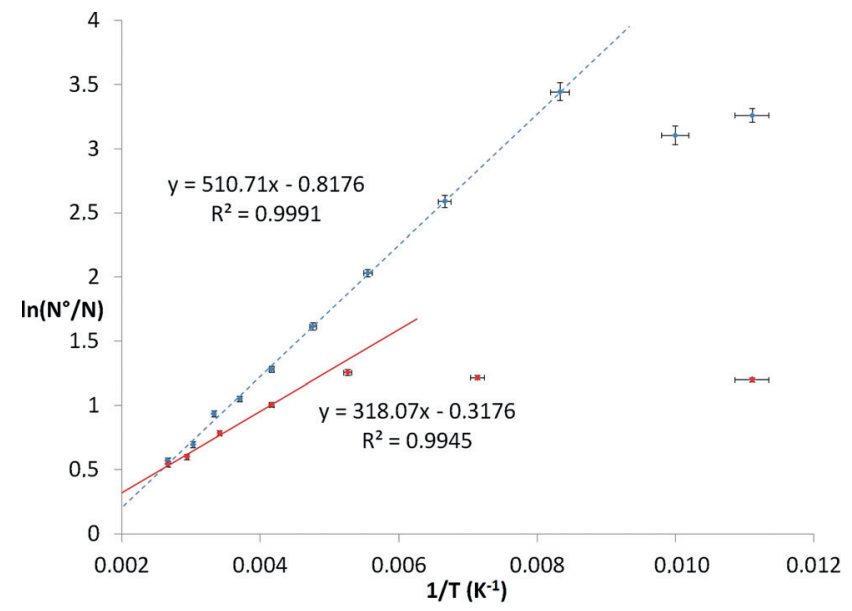

Fig. 2 Van't Hoff plot for compounds 1 (blue, dotted) and 2 (red).

Table 2 Enthalpy and entropy differences for compounds 1 and 2

\begin{tabular}{lll}
\hline & $-\Delta H\left(\mathrm{~kJ} \mathrm{~mol}^{-1}\right)$ & $\Delta S\left(\mathrm{~J} \mathrm{~K}^{-1} \mathrm{~mol}^{-1}\right)$ \\
\hline $\mathbf{1}$ & 4.3 & +6.8 \\
2 & 2.6 & +2.6 \\
\hline
\end{tabular}

observation and to chart the intermolecular interaction energies in the crystal, we performed computationally extremely cheap Atom-Atom Coulomb-London-Pauli (AA-CLP) calculations using the CLP program ${ }^{24}$ for both conformers. ${ }^{25}$

Two approaches were used, the first one by quite simply increasing the population of the minor and major conformer respectively to $100 \%$ in the CIF and removing the other conformer. The second approach is somewhat more refined, and involved placing the minor conformer in a supercell so it would be surrounded by only molecules of the major conformer. The results for this minor disorder component can then be directly compared to a CLP calculation on the structure containing major conformer only. These latter calculations confirm that the main stabilizing interactions for $\mathbf{1}$ are between parallel displaced molecules (44.8 $\mathrm{kJ} \mathrm{mol}^{-1}$ ), followed by molecules perpendicular to each other in the herringbone pattern $\left(25.6 \mathrm{~kJ} \mathrm{~mol}^{-1}\right)$. Between the herringbone packed layers perpendicular to the $a$-axis, pairwise interaction energies between the molecules are much lower at $10.4 \mathrm{~kJ} \mathrm{~mol}^{-1}$ and are mainly due to type II halogen interactions. In 2, a similar picture emerges - the largest stabilization is between parallel displaced molecules $\left(49.9 \mathrm{~kJ} \mathrm{~mol}^{-1}\right)$, followed by molecules interacting mainly via $\mathrm{C}-\mathrm{H} \cdots \mathrm{N}$ interactions between the layers $\left(15.7 \mathrm{~kJ} \mathrm{~mol}^{-1}\right)$ and, finally, the end-toend contacts with type II halogen interactions contribute an additional $11.2 \mathrm{~kJ} \mathrm{~mol}^{-1}$. All intermolecular interactions in the two structures are dominated by the dispersion term. The resulting total calculated intermolecular stabilization energies can be found in Table 3.

It is clear from these numbers that compound $\mathbf{1}$ displays a much larger energy difference between the two conformers in the crystal, where the values for $1\left(17.8 v s .9 .6 \mathrm{~kJ} \mathrm{~mol}^{-1}\right)$ are, for both models, somewhat more than double those of 2 (7.1 vs. $3.5 \mathrm{~kJ} \mathrm{~mol}^{-1}$ ). These results of the calculations are in accordance with the relative size of the experimentally observed enthalpy differences between the conformers $\left(\Delta H_{\text {obs }}\right.$ in Table 3), with the values for the second approach, quite reasonably, also being closer in value to the experimental observations. That the observed values themselves are smaller than the calculated ones is also reasonable, since the molecules in the matrix used for the calculation are unable to adapt their coordinates to the presence of a molecule of minor conformer.

In addition, the calculations clearly pinpoint the differences between the high and low occupancy conformers in the crystal structures. Discussion of the relevant calculated energies will be done for the low occupancy conformer in a matrix of high occupancy conformer only, but essentially the conclusions are identical for the simpler model in which all molecules are replaced with low occupancy conformer. For 2, there is no particularly striking change in the intermolecular interactions on switching conformers-they all become somewhat less attractive in the dispersion term, and/or a bit more repulsive in the repulsion term. This is most obvious for symmetry equivalents $-x, y+1 / 2,-z+1 / 2$, and $-x, y-1 / 2,-z+$ $1 / 2$, for which the dispersion term decreases most. For 1 , however, there are two clear culprits for the much larger difference in intermolecular energy in the crystal for high and low occupancy conformers: the interactions between molecules at $x, y, z$ and $x+1, y, z$ (the end-to-end type II halogen interaction) become less attractive by both coulomb interactions and dispersion $\left(20.3 \mathrm{~kJ} \mathrm{~mol}^{-1}\right)$ and at the same time become less repulsive by only $-14 \mathrm{~kJ} \mathrm{~mol}^{-1}$.

Fig. 3 clearly shows why: as the $-\mathrm{CH}_{2} \mathrm{Br}$ substituent is oriented meta with respect to the pedaling $\mathrm{N}=\mathrm{N}$ fragment, there is a sizeable reduction in distance between two opposite $-\mathrm{CH}_{2} \mathrm{Br}$ substituents upon switching to the minor conformer, which in turn causes considerable strain in the structure.

At the same time, the interaction between molecules $x, y$, $z$ and $x+1, y+1, z$ becomes on the one hand $-32.1 \mathrm{~kJ} \mathrm{~mol}^{-1}$ more attractive by coulomb interactions and dispersion, but on the other hand more repulsive by $36.4 \mathrm{~kJ} \mathrm{~mol}^{-1}$.

This is a clear demonstration of why geometric arguments in discussing crystal structures can be misleading. Based on geometry, a contact below the van der Waals radius appears between the molecules along $b$, and this would usually be interpreted as attractive. Some relevant distances are shown in Fig. 4. From the intermolecular energies, we know, however, that in this case the close contact is serendipitous and repulsive.

\section{Activation energy}

A different effect of the crystal structure on the pedal motion can be found in its activation energy, which is jointly determined by the electronic energy of a single molecule, and by the intermolecular interactions with the rest of the crystal. ${ }^{26}$ 
Table 3 Calculated intermolecular energies by the AA-CLP method for compounds 1 and 2

\begin{tabular}{|c|c|c|c|}
\hline \multicolumn{4}{|c|}{$\Delta E_{\mathrm{im}, \mathrm{calc}}\left(\mathrm{kJ} \mathrm{mol}^{-1}\right)$} \\
\hline & $\begin{array}{l}\text { Low occupancy } \\
\text { conformer }\end{array}$ & $\begin{array}{l}\text { Low occupancy conformer in } \\
\text { high occupancy matrix }\end{array}$ & $\begin{array}{l}\text { High occupancy } \\
\text { conformer }\end{array}$ \\
\hline 1 & -116.4 & -124.6 & -134.2 \\
\hline 2 & -132.8 & -136.4 & -139.9 \\
\hline \multicolumn{3}{|c|}{$\Delta \Delta E_{\mathrm{im}, \mathrm{calc}}\left(\mathrm{kJ} \mathrm{mol}^{-1}\right)$} & $\Delta H_{\text {obs }}\left(\mathrm{kJ} \mathrm{mol}^{-1}\right)$ \\
\hline 1 & 17.8 & 9.6 & 4.3 \\
\hline 2 & 7.1 & 3.5 & 2.6 \\
\hline
\end{tabular}

This activation energy determines at what temperature the pedal motion thaws out, which can be observed in the van't Hoff plots (Fig. 2) as the end of the horizontal plateau at low temperatures. Naively, one would expect a low activation energy to be determined by electronic energies only, with very little interference from the surrounding structure - but the picture is more nuanced than that, as will be seen below.

In order to quantify the effect of the crystal packing on the activation energy, we calculated non-equilibrium gas phase electronic energies for $\mathbf{1}$ and 2, where all bond distances, angles and torsion angles were relaxed, except the torsion angles around the central $\mathrm{N}=\mathrm{N}$ bond, which were given fixed values of $0^{\circ}$ to $180^{\circ}$ with $30^{\circ}$ increments.

The calculated energy profiles are very similar for both compounds, and are almost perfectly symmetrical around the planar conformations. The energies for all calculated points can be found in the ESI. $\dagger$ Energies for the respective low and high occupancy conformers of 1 and 2 at $0^{\circ}$ and $180^{\circ}$ are almost identical, and the conformations with the central double bond at $90^{\circ}$ have also quasi-identical relative energies of approximately $+51 \mathrm{~kJ} \mathrm{~mol}^{-1}$ for both compounds. In order to determine the (de)stabilization of the transition state through interactions with the rest of the crystal structure, we continued our computationally cheap approach of using the CLP program, and generated coordinates for a transition-state-like molecule. This geometry is the average of the geometries of the major and minor conformer (which yields reasonable

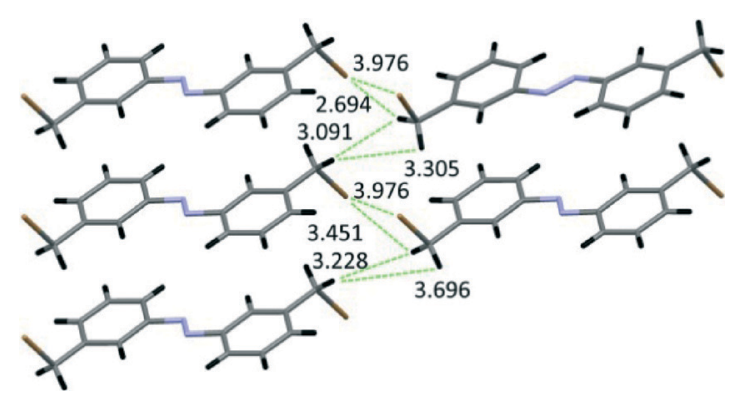

Fig. 3 Packing diagram along $b$ of low occupancy conformer (top right) and high occupancy conformer (bottom right) of 1, in a matrix of high occupancy conformer of 1 , with selected distances (in $\AA$ ) indicated by dotted green lines. bond distances and angles) in which the central double bond was then rotated to $90^{\circ}$ out of the plane of the rings, conserving the $\mathrm{C}-\mathrm{C}$ distances, and leaving all other coordinates unaffected. This transition-state-like molecule was again placed in a matrix of high occupancy conformer, and the same CLP method was applied to it, yielding the intermolecular energies between the transition-state-like molecule and the major conformer. By adding the calculated electronic energy differences to these numbers, we can obtain a rough idea of what the energy landscape of the system in the crystal would look like (Table 4).

We now see that the activation energies starting from the major conformer $\left(180^{\circ}\right)$ are always larger than those from the minor conformer. Experimentally, we find that the thawing out of the pedaling motion in 2 occurs at considerably higher temperatures when compared to $1(200 \mathrm{~K} v s .120 \mathrm{~K})$. The difference in the smallest activation energies between 1 and 2 amounts to $8.5 \mathrm{~kJ} \mathrm{~mol}^{-1}$, which confirms the observations, but is not a sufficiently large difference to explain the experimental discrepancy in thawing-out temperatures.

However, again the method does lead to new insights: the contribution of the crystal energy in the "transition state crystal" is not per se destabilizing at all, but in this case either lies between the energies of the planar conformers (in 2) or is even more stabilized than either planar conformer (in 1)! Since the electronic energies of the transition states are quasi equal, these small energy differences are crucial in determining the difference in total transition state energy for the pedal motion between these two compounds.

\section{Experimental}

\section{Synthesis}

(1E)-1,2-Bis[3-(bromomethyl)phenyl]-diazene 1. Prepared as described previously. ${ }^{7} \mathrm{Mp}: 146-147{ }^{\circ} \mathrm{C}$ (lit. 141-143). $R_{\mathrm{f}}=$ $0.41\left(\mathrm{CH}_{2} \mathrm{Cl}_{2} /\right.$ cyclohexane, $\left.1: 2\right)$. $\delta_{\mathrm{H}}\left(200 \mathrm{MHz}, \mathrm{CDCl}_{3}, \mathrm{TMS}\right)$ : 4.59 (s, 4H), 7.47-7.56 (m, 4H), 7.85-7.90 (m, 2H), 7.95-7.96

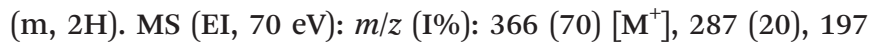
(50), 169 (100).

(1E)-1,2-Bis[4-(bromomethyl)phenyl]-diazene 2. Prepared as described previously. ${ }^{7} \mathrm{Mp}$ : $219-225{ }^{\circ} \mathrm{C}$ (decomp.) (lit. 217218). $R_{\mathrm{f}}=0.34\left(\mathrm{CH}_{2} \mathrm{Cl}_{2} /\right.$ cyclohexane, $\left.1: 2\right) . \delta_{\mathrm{H}}(200 \mathrm{MHz}$, $\left.\mathrm{CDCl}_{3}, \mathrm{TMS}\right): 4.56(\mathrm{~s}, 4 \mathrm{H}), 7.52-7.56(\mathrm{~m}, 4 \mathrm{H}), 7.88-7.92(\mathrm{~m}$,

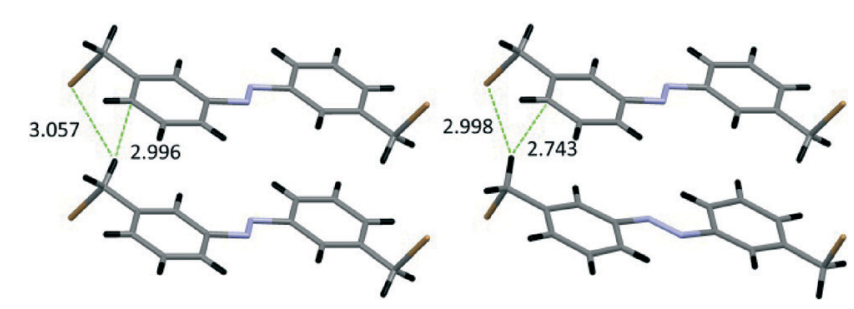

Fig. 4 Packing diagram along $\mathrm{c}$ of high occupancy conformer of 1 (left) and low occupancy conformer of 1 in matrix of high occupancy conformer (right). Selected distances (Å) indicated by dotted green lines. 
Table 4 Calculated activation energies ( $\left.\Delta E_{\text {act,calc }}\right)$ by summing gas phase electronic energies $\left(\Delta E_{\text {electr }}\right)$ with CLP molecular energies in the crystal $\left(\Delta E_{\mathrm{im}, \mathrm{CLP}}\right)$ for ground and pseudo-transition states. All energies in $\mathrm{kJ} \mathrm{mol}^{-1}$

\begin{tabular}{|c|c|c|c|c|c|}
\hline Angle & $0^{\circ}$ & & $90^{\circ}$ & & $180^{\circ}$ \\
\hline \multicolumn{6}{|l|}{1} \\
\hline$\Delta \mathrm{E}_{\mathrm{im}, \mathrm{CLP}}$ & -124.6 & & -134.3 & & -134.2 \\
\hline$\Delta \mathrm{E}_{\text {electr }}$ & 0 & & 50.9 & & 0 \\
\hline$\Delta \mathbf{E}_{\text {total }}$ & -124.6 & & -83.4 & & -134.2 \\
\hline$\Delta \mathrm{E}_{\mathrm{act}, \mathrm{calc}}$ & & 41.2 & & 50.8 & \\
\hline \multicolumn{6}{|l|}{2} \\
\hline$\Delta \mathrm{E}_{\mathrm{im}, \mathrm{CLP}}$ & -136.4 & & -137.7 & & -139.9 \\
\hline$\Delta \mathrm{E}_{\text {electr }}$ & 0 & & 51.0 & & 0 \\
\hline$\Delta \mathrm{E}_{\text {total }}$ & -136.4 & & -86.7 & & -139.9 \\
\hline$\Delta \mathrm{E}_{\text {act,calc }}$ & & 49.7 & & 53.2 & \\
\hline
\end{tabular}

4H). MS (EI, $70 \mathrm{eV}): m / z$ (I\%): $366(60)\left[\mathrm{M}^{+}\right], 287$ (100), 208 (90), 197 (20), 169 (50).

\section{X-ray diffraction}

Data sets were collected on a Bruker platform goniometer with Smart Apex detector, using Mo $\mathrm{K}_{\alpha}$ radiation (0.71073 ̊) from a sealed tube, monochromated with pyrrolithic graphite, and collimated with a pinhole collimator. Crystals were mounted on Mitegen micromesh mounts with a trace of glue and cooled or heated with an Oxford Cryostream cryostat. Temperature was ramped down from room temperature to 90(2) $\mathrm{K}$ at a speed of $4 \mathrm{~K} \mathrm{~min}^{-1}$ and data collections were carried out on heating in $30 \mathrm{~K}$ intervals, with a final dataset at $375(2) \mathrm{K}$ for 1 . Compound 2 was cooled at $4 \mathrm{~K} \mathrm{~min}^{-1}$ to $90(2) \mathrm{K}$, and then reheated in $50 \mathrm{~K}$ intervals, with a final dataset also at $375(2) \mathrm{K}$. Data were reduced with the Bruker APEX2 ${ }^{27}$ software suite and scaled and corrected for absorption effects using SADABS-2008/1. ${ }^{28}$ The structures were solved by direct methods with the help of SHELXS97 ${ }^{29}$ and refined using SHELXL2013/2, SHELXL2014/ $/ 7^{30}$ and shelXle. ${ }^{31}$ A model was constructed for each of the structures in which the 1,2- and 1,3-distances for the minor conformer were restrained to those in the major conformer. In addition, the ADPs of corresponding atoms were kept identical. These initial models were used unchanged for the refinements at all temperatures, in order to ensure comparability between the resulting populations of the disorder. H-atoms were refined as riding. The experimental data on the crystallographic experiments in this paper can be found in Tables S1 and S2 in the ESI $\dagger^{\dagger}$ CIF files are available as CCDC deposition numbers 1063365-1063374 (1) and 1065337510653381 (2).

\section{Calculations}

AA-CLP calculations were done with the CLP program, version of $05-2014$, employing the UNI force field, ${ }^{24}$ starting from the crystal geometries at $90 \mathrm{~K}$ and deriving $\mathrm{H}$-atom positions from the carbon skeleton. CIF files for the structures incorporating major or minor conformers only were generated by simply omitting the other coordinate set from the CIF. CIF files for the supercell structures were generated manually for both minor and major conformers by expanding the structure to space group $P 1$, and doubling or tripling unit cell axes as required. Conformers could then easily be changed from major to minor to obtain the desired configuration. These files are available as ESI $\dagger$ Gas phase electronic structure calculations were done at the DFT/B3LYP/6-31+G* level with Gaussian $09^{32}$ starting from the crystal geometries. For the calculation of the pseudo-transition states, partial optimizations were done with the torsion angles of the central double bond fixed at $30^{\circ}$ increments. Energies and geometries can be found in the ESI. $\dagger$

\section{Conclusions}

The pedal motion of the $\mathrm{N}=\mathrm{N}$ double bond of two azobenzene derivatives in the crystalline state closely follows the pattern observed before in stilbene, 4,4'-dimethylbenzylideneaniline and azobenzene, with similar values for $\Delta H$ and $\Delta S$, and does not resemble the aberrant pattern found thus far only in 2,4-dimethoxy-4'-nitrodistyrylbenzene. The large change in enthalpy difference and thus in temperature dependent conformational behavior between the structures 1 and 2 is largely due to the extension in length of the $m$-substituted molecule 1 on changing conformation, which puts a strain on the crystal structure. This increase in length does not occur for the $p$-isomer 2 , which consequently shows a much lower enthalpy difference between the conformers. The ratio of the observed enthalpy differences between the conformers is reproduced by various approaches to AA-CLP calculations with the CLP program, employing the UNI force field. Also the difference in the thawing-out temperature of the equilibria can be qualitatively explained by intermolecular interactions in the crystal influencing the activation energy of the pedaling motion.

\section{Acknowledgements}

The X-ray diffractometer was funded by NSF grant 0087210, Ohio Board of Regents Grant CAP-491, and by Youngstown State University. The authors wish to thank Dr. Davy Geldof and Prof. Dr. Frank Blockhuys (University of Antwerp) for useful discussions, running the Gaussian calculations and providing computer time.

\section{Notes and references}

1 E. Merino, Chem. Soc. Rev., 2011, 40, 3835-3853.

2 H. Rau, Angew. Chem., Int. Ed. Engl., 1973, 12, 224-235.

3 H. M. D. Bandara and S. C. Burdette, Chem. Soc. Rev., 2012, 41, 1809-1825.

4 E. Merino and M. Ribagorda, Beilstein J. Org. Chem., 2012, 8, 1071-1090.

5 S. Shinkai, T. Minami, Y. Kusano and O. Manabe, J. Am. Chem. Soc., 1983, 105, 1851-1856.

6 M. Bauer, W. M. Müller, U. Müller, K. Rissanen and F. Vögtle, Liebigs Ann., 1995, 649-656. 
7 B. Jousselme, P. Blanchard, N. Gallego-Planas, E. Levillain, J. Delaunay, M. Allain, P. Richomme and J. Roncali, Chem. Eur. J., 2003, 9, 5297-5306.

8 R. S. Stoll, M. V. Peters, A. Kühn, S. Heiles, R. Goddard, M. Bühl, C. M. Thiele and S. Hecht, J. Am. Chem. Soc., 2009, 131, 357-367.

9 V. A. Azov, J. Cordes, D. Schlüter, T. Dülcks, M. Böckmann and N. L. Doltsinis, J. Org. Chem., 2014, 79, 11714-11721.

10 J. Harada and K. Ogawa, Chem. Soc. Rev., 2009, 38, 2244-2252.

11 J. Harada, K. Ogawa and S. Tomoda, Acta Crystallogr., Sect. B: Struct. Sci., 1997, 53, 662-672.

12 J. Harada and K. Ogawa, J. Am. Chem. Soc., 2001, 123, 10884-10888.

13 J. D. Protasiewicz, M. P. Washington, V. B. Gudimetla, J. L. Payton and M. C. Simpson, Inorg. Chim. Acta, 2010, 364, 39-45.

14 J. Harada, K. Ogawa and S. Tomoda, Acta Crystallogr., Sect. B: Struct. Sci., 1995, 51, 240-248.

15 A. N. Sokolov, D. C. Swenson and L. R. MacGillivray, Proc. Natl. Acad. Sci. U. S. A., 2008, 105, 1794-1797.

16 R. Singh, M. Ahmad and P. K. Bharadwaj, Cryst. Growth Des., 2012, 12, 5025-5034.

17 M. K. Sharma and P. K. Bharadwaj, Inorg. Chem., 2011, 50, 1889-1897.

18 A. Natarajan, J. T. Mague, K. Venkatesan, T. Arai and V. Ramamurthy, J. Org. Chem., 2006, 71, 1055-1059; A. M. P. Peedikakkal and J. J. Vittal, Chem. - Eur. J., 2008, 14, 5329-5334; L. G. Kuz'mina, A. I. Vedernikov, S. K. Sazonov, N. A. Lobova, A. V. Churakov, E. Kh. Lermontova, J. A. K. Howard, M. V. Alfimov and S. P. Gromov, Russ. Chem. Bull., 2011, 60, 1734-1761; E. Elacqua, P. Kaushik, R. H. Groeneman, J. C. Sumrak, D. K. Bucar and L. R. MacGillivray, Angew. Chem., Int. Ed., 2012, 51, 1037-1041.

19 P. Rajakannu, F. Hussain, B. Shankar and M. Sathiyendiran, Inorg. Chem. Commun., 2012, 26, 46-50.

20 J. Harada and K. Ogawa, J. Am. Chem. Soc., 2004, 126, 3539-3544.

21 J. Harada, M. Harakawa and K. Ogawa, Acta Crystallogr., Sect. B: Struct. Sci., 2004, B60, 589-597.
22 C. M. L. Vande Velde, A. Collas, R. De Borger and F. Blockhuys, Chem. - Eur. J., 2010, 17, 912-919.

23 V. R. Pedireddi, D. S. Reddy, B. S. Goud, D. C. Craig, A. Rae and G. R. Desiraju, J. Chem. Soc., Perkin Trans. 2, 1994, 2352-2360; P. Metrangolo, H. Neukirch, T. Pilati and G. Resnati, Acc. Chem. Res., 2005, 38, 386-395; P. Metrangolo, F. Meyer, T. Pilati, G. Resnati and G. Terraneo, Angew. Chem., Int. Ed., 2008, 47, 6114-6127.

24 A. Gavezzotti, New J. Chem., 2011, 35, 1360-1368.

25 The gas phase electronic energies of both conformers for both compounds are equal up to the accuracy of DFT calculations at the B3LYP/6-31+G* level $\left(<0.25 \mathrm{~kJ} \mathrm{~mol}^{-1}\right)$.

26 J. Harada and K. Ogawa, Cryst. Growth Des., 2014, 14, 5182-5188.

27 APEX2, Bruker AXS Inc., Madison, Wisconsin, USA, 2012.

28 SADABS-2008/1, Bruker AXS Inc., Madison, Wisconsin, USA, 2008.

29 G. M. Sheldrick, Acta Crystallogr., Sect. A: Found. Crystallogr., 2008, 64, 112-122.

30 G. M. Sheldrick, SHELXL2013/2, University of Göttingen, Germany, 2013; G. M. Sheldrick, SHELXL2014/7, University of Göttingen, Germany, 2014.

31 C. B. Hübschle, G. M. Sheldrick and B. Dittrich, J. Appl. Crystallogr., 2011, 44, 1281-1284.

32 M. J. Frisch, G. W. Trucks, H. B. Schlegel, G. E. Scuseria, M. A. Robb, J. R. Cheeseman, G. Scalmani, V. Barone, B. Mennucci, G. A. Petersson, H. Nakatsuji, M. Caricato, X. Li, H. P. Hratchian, A. F. Izmaylov, J. Bloino, G. Zheng, J. L. Sonnenberg, M. Hada, M. Ehara, K. Toyota, R. Fukuda, J. Hasegawa, M. Ishida, T. Nakajima, Y. Honda, O. Kitao, H. Nakai, T. Vreven, J. A. Montgomery Jr., J. E. Peralta, F. Ogliaro, M. Bearpark, J. J. Heyd, E. Brothers, K. N. Kudin, V. N. Staroverov, R. Kobayashi, J. Normand, K. Raghavachari, A. Rendell, J. C. Burant, S. S. Iyengar, J. Tomasi, M. Cossi, N. Rega, J. M. Millam, M. Klene, J. E. Knox, J. B. Cross, V. Bakken, C. Adamo, J. Jaramillo, R. Gomperts, R. E. Stratmann, O. Yazyev, A. J. Austin, R. Cammi, C. Pomelli, J. W. Ochterski, R. L. Martin, K. Morokuma, V. G. Zakrzewski, G. A. Voth, P. Salvador, J. J. Dannenberg, S. Dapprich, A. D. Daniels, Ö. Farkas, J. B. Foresman, J. V. Ortiz, J. Cioslowski and D. J. Fox, Gaussian 09, Revision A.02, Gaussian, Inc., Wallingford CT, 2009. 